\title{
Mediações e Sense-Making: duas lógicas comunicacionais do Design da Informação
}

\author{
Mediations and Sense-Making: two communication \\ logics of Information Design
}

Júlia Rabetti Giannella, Sandra Souza

design da informação, mediações, sense-making

information design, mediations, sense-making
No contexto de excesso de dados e valorização do tempo, a transformação de dados brutos em informação significativa pelas técnicas e princípios do Design da Informação se dá por meio de duas orientações não excludentes, porém distintas, de comunicação: a lógica das mediações (Martín-Barbero) pela qual as mídias têm gerado e difundido, geralmente de modo controlado, seus conteúdos (e, consequentemente, o conhecimento deles derivado) e a lógica do Sense-Making (Dervin), pela qual usuários, junto com as mídias ou além delas, se permitem a construção e difusão do conhecimento de uma realidade que é ordenada e caótica. O artigo esclarece essas duas lógicas comunicacionais e as ilustra por meio da análise de um infográfico interativo intitulado The electoral map: building a path to victory, publicado pelo The New York Times durante as eleições presidenciais de 2012 nos Estados Unidos.

In the age of data overload and awareness that time is a valuable thing, raw data transformation into meaningful information by the techniques and principles of Information Design is given by two non-exclusive, but distinct, communication approaches: the logic of mediations (Martín-Barbero) through which the media generates and distributes, usually in a controlled manner, their contents (and, consequently, the knowledge derived therefrom) and Sense-Making logic (Dervin), whereby users, along with the media or beyond it, are allowed the possibility of knowledge construction and dissemination of a reality assumed to be both orderly and chaotic. The article clarifies these two communication logics and illustrates them through the analysis of an interactive infographic named The electoral map: building a path to victory, published by The New York Times during the presidential elections of 2012 in the United States.

\section{Introdução}

O Design da Informação atua no processo comunicacional facilitando a compreensão de uma mensagem por meio da organização, codificação e apresentação de determinada informação. A produção teórica do Design da Informação é relativamente escassa quando 
1 Existem divergências a respeito do início das atividades constituintes básicas do Design da Informação. Horn (2000: 17) identifica a origem e história do Design de Informação a partir de invenções de unidades comunicativas específicas (gráfico de barras e linhas do tempo, por exemplo), o que só teria ocorrido no século XVIII. Já Meggs e Purvis (2009: 18-19) reconhecem nas pinturas rupestres nas marcas, símbolos, figuras e letras traçadas ou escritas sobre uma superfície - formas naturais de comunicar ideias, de registrar e transmitir informação. Já Dervin (2000: 36) argumenta que o Design da Informação se faz presente nas atividades humanas desde antes do surgimento das tecnologias digitais. comparada à de outras disciplinas: embora alguns autores reconheçam a prática do Design da Informação desde as primordiais pinturas das cavernas do homem pré-histórico ${ }^{1}$, o exercício intelectual e acadêmico a seu respeito é recente e pouco sistematizado.

Assim como ocorre em outras áreas do Design, a prática do Design da Informação é centrada no usuário e dependente do contexto em que ela se realiza, o que dificulta uma metodologia que possa ser replicada na análise e avaliação de seus objetos. Se não há receitas para o Design da Informação, contudo, existem aspectos fundamentais de comunicação que são tradicionalmente considerados durante seu processo de concepção para que a mensagem chegue a seus destinatários de modo eficaz, a saber: a definição dos objetivos (por quê? para quê?); a quem se dirige (para quem?), a definição do contexto (onde e quando?) e a estrutura da informação (por quais meios? como?).

Horn (2000), ao defender que o Design da Informação é uma das mais recentes manifestações da Comunicação, o definiu como "[...] a arte ou a ciência de preparar a informação de maneira que ela possa ser usada pelos indivíduos com mais eficiência e efetividade" (Horn, 2000: 15). O autor identifica três objetivos para o Design da Informação:

1. desenvolver documentos que sejam compreensíveis, de assimilação rápida e precisa, e facilmente convertidos em ações efetivas;

2. projetar interações fáceis, naturais e prazerosas para interfaces homem-computador;

3. auxiliar pessoas a encontrar caminhos em espaços tridimensionais com conforto e facilidade, especialmente em ambientes urbanos, mas também em espaços virtuais. (Horn, 2000: 15-16)

Esses três objetivos podem ser encaminhados para finalidade mais geral e ampla: "[...] assegurar a efetividade da comunicação mediante a facilitação dos processos de percepção, leitura, compreensão, memorização e uso da informação apresentada" (Frascara, 2011: 11, grifo nosso). Com essas palavras, Frascara sugere que a essência do Design de Informação é centrada no usuário e em suas necessidades, o que faz com que o objetivo primordial de sua atividade se desloque da produção de objetos em si para a produção de sentidos para e pelo público.

Justamente porque são produzidos para serem usados - o que estabelece sua intencionalidade pragmática - os produtos do Design da Informação afastam-se de certas faculdades do Design Gráfico e das Belas Artes, sem as excluir: aspectos estilísticos e estéticos devem ser secundários em relação aos princípios de claridade, precisão, legibilidade, compreensibilidade e simplicidade (Horn, 2000: 25), que operam para que a informação se torne acessível, apropriada, atrativa, confiável, concisa, completa, relevante, oportuna e compreensível (Frascara, 2011: 10). 
Do ponto de visto da produção, o processo do Design da Informação ocorre em dois momentos distintos: a organização da informação e a codificação-implementação de sua apresentação visual. Essas tarefas requerem habilidades interdisciplinares para processar, organizar e apresentar a informação em formas linguísticas (escrita) e não linguísticas (a imagem em seu sentido mais amplo), e resultam em uma multiplicidade de sistemas texto-visuais como, por exemplo, design editorial (projeto gráfico de livros, diagramação de material didático); tabelas alfanuméricas (horários e diversos tipos de tabelas); representações esquemáticas (gráficos, diagramas, mapas e infográficos); documentos administrativos (formulários, boletos); instruções visuais (manuais, regras de jogos, bulas de remédios); sistemas de sinalização; catálogos, programas, prospectos de exposições; interfaces para meios eletrônicos (Frascara, 2011: 9-10).

Para Pasquall (2005: 5), o termo informação pode ser rastreado desde a era clássica “[...] denotando a interpenetração ou imposição de uma forma, ideia ou princípio, com ou em matéria, que assim se tornava 'in-formada' ou 'formada'". Informar, historicamente, sugere uma mensagem transmitida unidirecionalmente a um receptor passivo que terá seu comportamento direta e imediatamente afetado. Em contraponto a esta visão tradicional de informação, emerge a concepção alternativa de Brenda Dervin (2000) que critica a relação impositiva e funcional que o termo adquiriu e insiste que se deva enfatizar a lógica construtiva e negociada da informação. Para a autora, informação é uma ferramenta projetada pelos homens para dar significado a uma realidade que é, ao mesmo tempo, caótica e ordenada. A partir deste novo paradigma para o conceito de informação, Dervin propõe uma teoria chamada Sense-Making que, por sua vez, estabelece uma abordagem comunicacional bidirecional para o exercício do Design da Informação.

Dentro da lógica Sense-Making, indivíduos, isolada ou coletivamente, participam dos processos de produção de sentido na medida em que exploram a informação em um diálogo interativo. Como consequência, "[...] o Design da Informação é, de fato, metadesign: design sobre design, design para ajudar indivíduos a fazer e desfazer suas próprias informações, seus próprios sentidos" (Dervin, 2000: 43). A perspectiva de Dervin encontra eco na defesa de Frascara (2011) de que mensagens produzidas pelo Design da Informação não são apenas transmitidas, mas sim interpretadas pelas pessoas (Frascara, 2011: 9). Para os autores trata-se, sobretudo, de um processo mediático entre dois atores $<$ emissor $>-<$ interpretante $>$. Estes atores serão designados neste artigo, a partir do enfoque de Shedroff (2000) apresentado na seção seguinte, como < produtor>$<$ consumidor $>$ de informação, no qual este último interagente busca estabelecer significações mediante processo interativo que amplifica sua cognição. A abordagem comunicacional Sense-Making, embora possa ser questionada em determinados contextos de uso em que é conveniente transmitir a informação de modo monossênico, 
2 Ansiedade da informação é a tradução da expressão information anxiety, cunhada por Wurman. constitui um contraponto ao modo tradicional de conceber produtos informacionais (notícias e infográficos, por exemplo) como processos formatados pelas mídias e desenvolvidos por produtores da informação com a finalidade de orientar a leitura a partir de contextos de uso pré-determinados. Esta lógica sedimentada pelos meios de comunicação para o exercício do Design da Informação será chamada de Mediações (Martín-Barbero ,1987) e voltaremos a ela ao longo deste artigo para discutir a origem do termo. O objetivo é demonstrar como Mediações e Sense-Making compõem lógicas comunicacionais distintas, mas não excludentes, na medida em que interagem, em graus diferentes, com os produtos do Design da Informação.

Nas seções seguintes, serão retomados conceitos fundamentais para o entendimento das duas lógicas comunicacionais (Mediações e Sense-Making). Parte-se do modelo teórico dado>informação>con hecimento $>$ sabedoria (Shedroff, 2000) para descrever o contexto de sobrecarga de dados digitais na sociedade contemporânea e evidenciar como este fenômeno potencializa o papel mediador do designer na redução da complexidade cognitiva e no processo de assimilação do conteúdo. Em seguida, problematiza-se a abordagem mediada e apresenta-se a lógica Sense-Making como alternativa não excludente à ideia das mediações. Conclui-se, analisando um infográfico interativo, publicado no The New York Times em 2012, no qual é possível contrastar a lógica das mediações com a lógica do Sense-Making operando conjuntamente dentro de um mesmo exemplo de Design da Informação.

\section{Comunicação para gerar sentido: do dado à sabedoria}

O aumento da quantidade de dados disponíveis requer ampliação do campo da arquitetura da informação, saber focado na combinação de princípios do design e da arquitetura em espaços digitais, para que os dados possam ser organizados e gerar sentido (Wurman, 1991). Diante desse cenário, o autor sugere que o grande desafio da chamada era da informação é evitar a ansiedade da informação ${ }^{2}$, isto é, evitar o buraco negro entre dado e conhecimento. 
Figura 1 DIKW model. (Fonte: Shedroff, 2000: 271.)

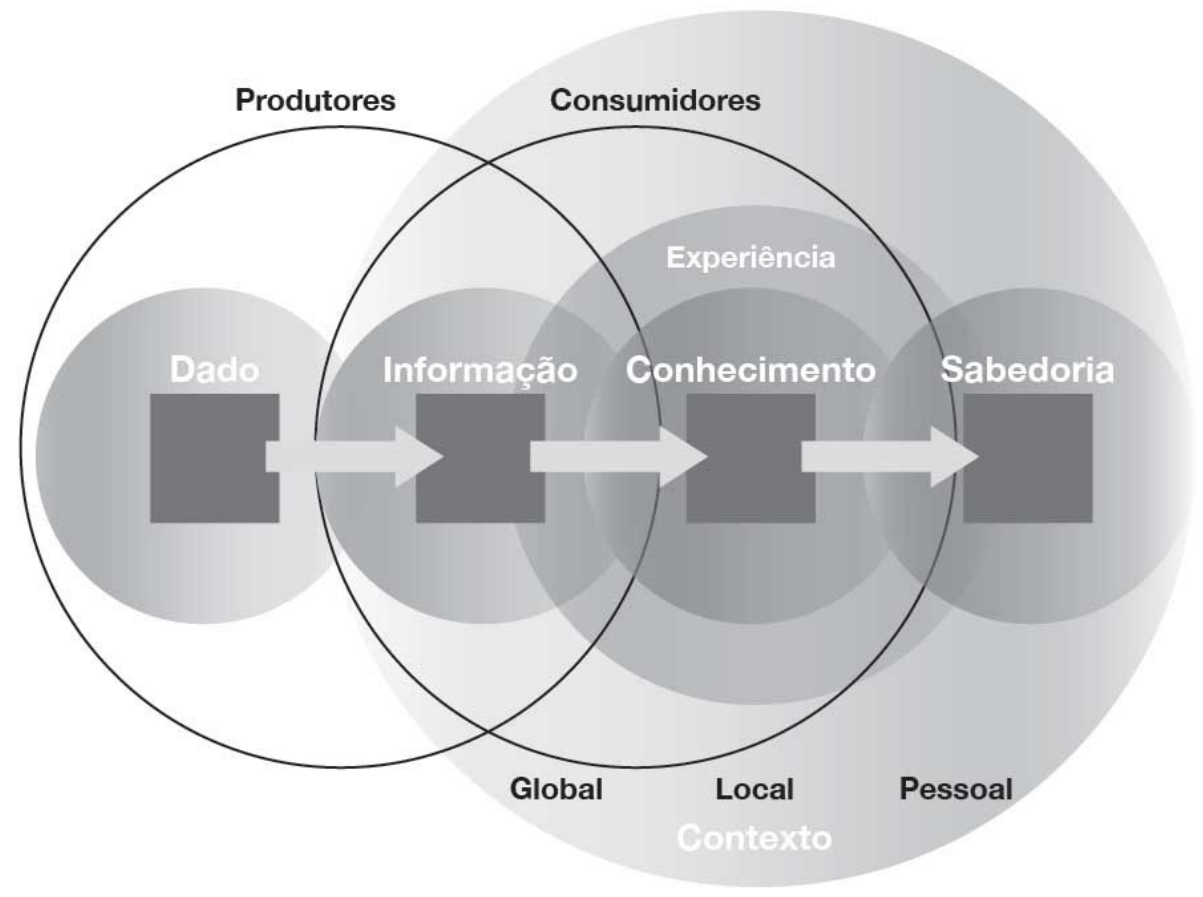

3 DIKW model é um modelo amplamente estudado no campo da arquitetura da informação. Diversos autores estudaram e reformularam o modelo, sendo o apresentado no presente trabalho oportuno para seus propósitos.
Essa lacuna é evidenciada na Figura 1, o DIKW model ${ }^{3}$ (data, information, knowledge, wisdom), esquema proposto por Shedroff (2000: 271) no qual os dois extremos da máxima de Wurman (dado e conhecimento) são apresentados.

Dados são produtos de pesquisa, criação, coleta ou descoberta. Constituem o material bruto utilizado na construção de mensagens comunicativas. Para ser entregues aos consumidores (usuários da informação), precisam transformar-se e organizar-se em informação, de maneira a revelar conteúdos e relações significativas. Essa transformação abrange, no mínimo, dois momentos do Design da Informação: 1) uma organização lógica dos dados e 2) uma apresentação apropriada da estrutura. É exatamente nessa transformação (dados>informação) que os comunicadores assumem suas funções mediadoras.

Conhecimento e sabedoria são etapas pertencentes à esfera dos consumidores da informação e correspondem a graus diferentes de compreensão das informações apresentadas, processadas e internalizadas por meio de experiências pessoais e intransferíveis. O conhecimento é a compreensão alcançada via a experiência do usuário e a sabedoria é a compreensão profunda do conhecimento adquirido, sendo extremamente pessoal e abstrata. Não podemos criar sabedoria assim como coletamos dados e os transformamos em informações, nem podemos compartilhá-la como fazemos com o conhecimento. A sabedoria constitui um nível de compreensão que só pode ser obtido individualmente. 


\footnotetext{
4 A expressão Big

Data é usada para descrever o acelerado crescimento de dados. Em 2001, o Grupo Gartner, Centro de Pesquisa em Tecnologia da Informação, estabelecido em Connecticut, Estados Unidos, definiu desafios e oportunidade do crescimento vertiginoso de dados por meio da avalição de três parâmetros: volume crescente (quantidade de dados), velocidade (fluxo de entrada e saída de dados) e variedade (tipos e fontes de dados).
}

O DIKW model apresenta um modelo do processo comunicacional a partir da possível continuidade entre as unidades dado e sabedoria. Dois agentes são retratados nesse modelo: produtores - que seriam os comunicadores - e consumidores - que seriam, em contrapartida, os usuários da informação. A interação entre esses dois polos agentes acontece no nível da informação que, por sua vez, se constitui, para o comunicador, na etapa de transformação de dados brutos em informações significativas, por meio de sua organização e apresentação e, para o usuário, no acesso traduzido e manipulado de dados para que, mediante suas experiências individuais e/ou coletivas, os significados possam ser assimilados. "O designer da informação assume, assim, o papel de mediador entre os dados brutos e suas apresentações em informações visualmente significativas, compreensíveis [e delimitadas] para o leitor "(Costa, 1998: 34, grifo nosso).

A apresentação clara, efetiva e imediata da informação constitui-se, pelo modelo teórico proposto por Shedroff (2000), como tarefa precedente fundamental ao processo de aquisição de conhecimento. A contribuição e crítica de Dervin a esse modelo de pensamento é que a finalidade do Design da Informação deve ir além de gerar sentido pré-definido nos consumidores. Em outras palavras, segundo a autora, a preocupação principal dos designers e comunicadores deve se deslocar da ideia de empacotar e distribuir um produto de modo eficaz e lucrativo para se debruçar em "como fazer coisas adquirirem sentido", para que pessoas em diferentes contextos, espaços e tempos possam superar lacunas, formulando e reformulando as mensagens que chegam até elas (Dervin, 2000: 43). Trata-se de um redirecionamento de lógica comunicacional que, no entanto, não deve excluir o papel das mediações e dos princípios e teorias do design (organização visual, hierarquização, cor, Gestalt, etc.).

\section{Comunicação na era de dados excedentes}

"Uma edição do The New York Times em um dia da semana contém mais informação do que o comum dos mortais poderia receber durante toda uma vida na Inglaterra do século XVIII" (Wurman, 1991: 36). Com essa afirmação, publicada originalmente em 1989, Wurman alerta para a velocidade da produção de informação que já se instituía na sociedade há três décadas e que hoje denomina-se como o fenômeno do Big Data ${ }^{4}$. A preocupação do autor dirigia-se ao fato de que o aumento gradativo de dados, fatos e números não gera, necessariamente, conhecimento, pois entre os dois níveis do DIKW model (dados e conhecimento) é preciso haver a transformação clara e significativa de dados em informação.

Três atividades podem ser associadas à difusão da informação no processo comunicacional: armazenamento, transmissão e compreensão (Wurman, 1991: 54). O modelo transmissionista (em 
issor $>$ mensagem $>$ canal $>$ receptor), que por muito tempo vigorou como modelo tradicional de comunicação de massa, atualmente renova-se para paradigmas mais dialógicos, nos quais: 1) transmissão atualiza-se em circulação (Fausto Neto, 2010); 2) o papel de receptor avança para as apropriações do usuário, interagente e interpretante e 3) as relações comunicativas, com base na ideia de causa e efeito, evoluem para uma concepção mais consensual e negociada, ainda que a lógica distribucionista continue presente em muitos contextos comunicacionais. Feita essa colocação, Wurman aponta que, enquanto as atividades de armazenamento e transmissão são diretamente otimizadas e desenvolvidas no contexto das tecnologias digitais (computador, hardware, software, base de dados, etc.) e pelo modelo multimídia e multilinear que a web constitui, existe um enfraquecimento da terceira atividade, a compreensão, sem a qual não existe Comunicação. Para o autor, profissionais dedicados à atividade de compreensão, responsáveis por ajudar pessoas a extrair significados dos mais diversos conteúdos, são aqueles a quem se recorreria para tornar compreensível, por exemplo, dados estatísticos do censo, formulários de seguro de saúde, relatórios anuais de empresa, etc. (Wurman, 1991: 55). O tratamento lógico e mediado da informação precede seu tratamento gráfico-visual e é, em regra, o resultado da intervenção político-criativa do ser humano ao delimitar e priorizar (e, consequentemente, reduzir) determinado domínio informativo em um número finito de dados relacionáveis entre si. "A redução lógica da informação é o meio pelo qual o homem pode aplicar ao maior conjunto possível de observações o número limitado de instantes de percepção que dispõe no curso de sua existência" (Bertin, 1970: 178).

As possibilidades de atuação do Design da Informação, assim como de outras atividades da Comunicação, são claramente ampliadas no contexto de excesso de dados e da valorização do tempo e da informação evidente em nossa sociedade. A partir da lógica comunicacional das mediações, o Design da Informação constitui-se como caminho decisivo para controlar a chamada explosão da (não-) informação e contribuir para sua gestão, tornando-se disciplina de considerável relevância social.

A combinação de escrita, imagens e números constitui, para Wurman (1991: 62), o acesso ao mundo compreensível. Enquanto imagens têm alta densidade informativa, palavras e números têm maior poder descritivo e de diferenciação, e é por isso que mesmo apresentações predominantemente visuais utilizam recursos linguísticos para representar determinadas unidades informativas. 
O projeto One Million (Figura 2) ilustra as potencialidades da visualidade e das mediações no discurso comunicativo. Além de possuir alta densidade informativa, certas modalidades de apresentação visual favorecem a compreensão de conteúdos gerados pelo grande fluxo de dados, pois elas possibilitam a visualização de conceitos abstratos, ou seja, conceitos mentais, como, por exemplo, comparações, proporções, evoluções, conexões e hierarquias (Frascara, 2011: 43).

Figura 2 Livro One Million. Fonte: Design Notes, $2010^{5}$

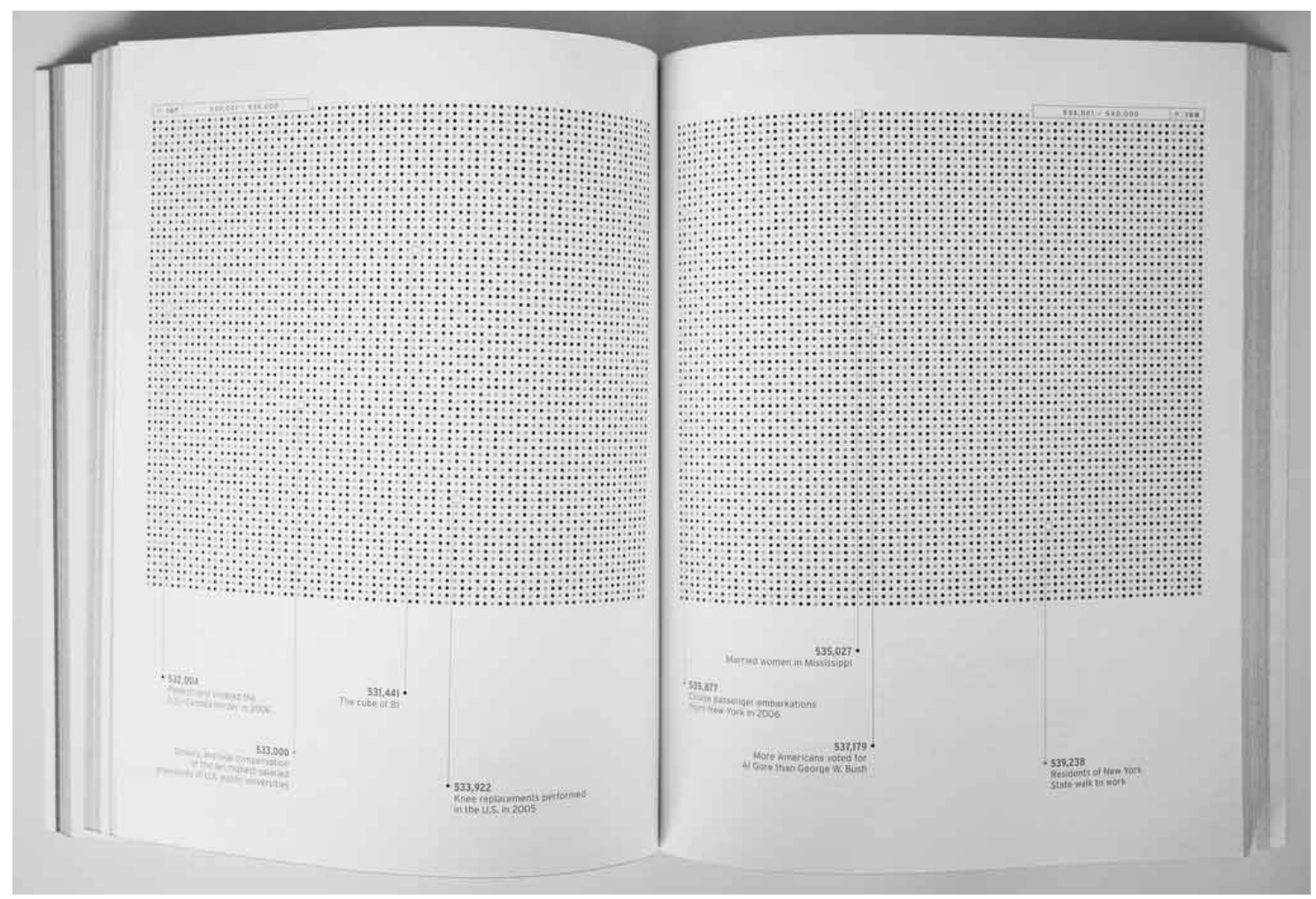

5 Disponível em:

$<$ http://designnotes. info/? $\mathrm{p}=3523>$.

Acesso em mar. 2015.
A ideia fundamental do projeto One Million, de Hendrik Hertzberg - que motivou a publicação, em 1970, do livro de título homônimo -, é tornar um número grande e abstrato, no caso um milhão, um valor mais tangível para os leitores. Uma base de dados em formato de planilha Excel, neste caso, não realizaria o segundo momento do Design da Informação - as etapas de codificação e implementação da apresentação visual - sem o qual leitores poderiam sentir-se perdidos diante de tanta informação. Dessa forma, Hertzberg projetou um livro em que cada uma de suas 200 páginas reúne 5.000 pontos, totalizando um milhão de pontos. Em cada página, alguns pontos, organizados numericamente, são selecionados e priorizados dentro de uma lógica de edição. Os valores desses números são apresentados por escrito, e algumas informações estatísticas relevantes e contextualizadas a respeito dos mesmos são narradas. 


\section{Mediações e Sense-Making: duas lógicas comunicacionais}

A ideia de mediação corresponde à percepção de que não há conhecimento direto da realidade e de que o acesso ao "real" é sempre intermediado por fatores humanos e contextuais (Braga, 2012: 32). Martín-Barbero (1987) compreende que não há uma definição singular para o termo e que é melhor pensá-lo como uma noção plural, mediações. Para o autor, o termo mediações sintetiza a comunicação a partir dos espaços nos quais é possível identificar a interação entre a produção e o consumo da informação. Há, dessa forma, o entendimento de que o polo produtor integra contexto, interesses e práticas sociais dos consumidores. Da mesma forma, Bonsiepe (2000: 6) assume que, exatamente no ponto de transformação dados>informação, designers atuam ao aplicar sua expertise na redução da complexidade cognitiva e na apresentação da informação por meio de uma interface que conjugue as fontes, as informações e os leitores. Pois bem, se há, segundo os autores citados, espaços para interlocução nos produtos da Comunicação - e aqui estamos particularmente interessados em discutir produtos do Design da Informação - pode-se perguntar, a essa altura, qual seriam as diferenças e aproximações entre as lógicas das mediações e do Sense-Making proposto por Dervin (2000).

Primeiramente, é preciso salientar que se entende a relação entre as lógicas das mediações e do Sense-Making como sendo de ênfase, e não de exclusão. A noção plural e ao mesmo tempo sintética das mediações, como defende Martín-Barbero, as constitui como processos amplos e polissêmicos, capazes de abarcar diferentes formas e orientações para entender as lógicas comunicacionais, das mais dirigidas às mais dialógicas e processuais, estas mais próximas da abordagem do Sense-Making, na medida em que enfatizam a informação como ferramenta para que consumidores participem mais individual e ativamente do processo de significação.

Dito isso, definem-se as mediações e o Sense-Making neste artigo como lógicas da Comunicação que impregnam o Design da Informação segundo modos de ser e de operar técnica e socialmente podendo ser associadas, respectivamente, a dois modelos tendenciais que as mídias praticam: o primeiro modelo, orientado tradicionalmente para o dirigismo, diz ao leitor o quê e como ele deve se informar; o segundo orienta-se para abertura da mídia e dos meios - o que coloca o consumidor-usuário como co-participante dos resultados e efeitos da informação sobre ele próprio e sobre a sociedade.

Para ilustrar como as lógicas comunicacionais das mediações e do Sense-Making operam em produtos do Design da Informação recorreu-se a um único exemplo analisado na dissertação de Giannella (2014) que buscou, dentre outros objetivos, investigar os diferentes gradientes de dirigismo por parte dos produtores e de exploração por parte dos consumidores-usuários em infográficos interativos baseados em dados. O fato de delimitarem-se, neste trabalho, as dimensões de aplicação para observar as lógicas comunicacionais - delimitações 


6 Dervin (2000)
não estabelece a
interatividade do tipo
homem-máquina como
pré-requisito para que
indivíduos constituam
processos dialógicos
e participativos com
a mensagem.

Dervin (2000) interatividade do tipo homem-máquina como prérequisito para que processos dialógicos a mensagem. que seriam, neste caso, quanto: a forma (sistemas texto-visuais esquemáticos), ao discurso (jornalístico) e ao meio (digital-interativo) - não deve impedir que a reflexão sobre as lógicas comunicacionais em produtos do Design da Informação possa ser estendida para outros contextos de uso.

A delimitação do meio - digital-interativo - merece uma observação mais atenta. O papel da interatividade na comunicação mediada pelo computador, assim como a popularização da Internet, são fundamentais para ampliação da lógica comunicacional de SenseMaking embora não a defina ${ }^{6}$. Longe de estabelecer um determinismo, compreende-se que os progressos tecnológicos e o impacto das novas mídias interativas podem proporcionar uma reorientação da sociedade e de suas práticas frente às informações, estabelecendo um processo que permite novas formas de produzi-las, circulá-las e consumi-las, de sentir, ver e interpretar o mundo.

The Electoral Map: building a path to victory, publicado pelo The New York Times em 2012, é um infográfico interativo baseado em dados a respeito da disputa eleitoral presidencial norte-americana. Um menu de navegação situado logo abaixo do título indica que o infográfico possui diversas telas e sugere, por meio da disposição e nome dos botões, que o acesso às mesmas seja realizado em ordem sequencial. Na primeira tela chamada Map (Figura 3), observa-se uma representação composta de quadrados posicionados nas duas dimensões do plano que correspondem, por associação geográfica, aos estados dos Estados Unidos. As áreas dos quadrados, que representam cada estado, são escalonadas proporcionalmente ao número de votos eleitorais que cada estado tem direito nas eleições presidenciais. As cores e tonalidades de cada quadrado associam-se ao candidato presidencial com maior probabilidade de vitória no local (Obama, representado em azul, e Romney, representado em vermelho) ou à situação de um possível empate (representada em amarelo). Este tipo de representação de mapa é chamado de cartograma. 


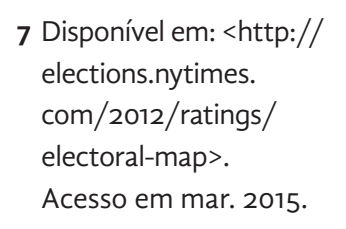

Figura 3 Tela Map do infográfico The Electoral Map. (Fonte: The New York Times, 20127).

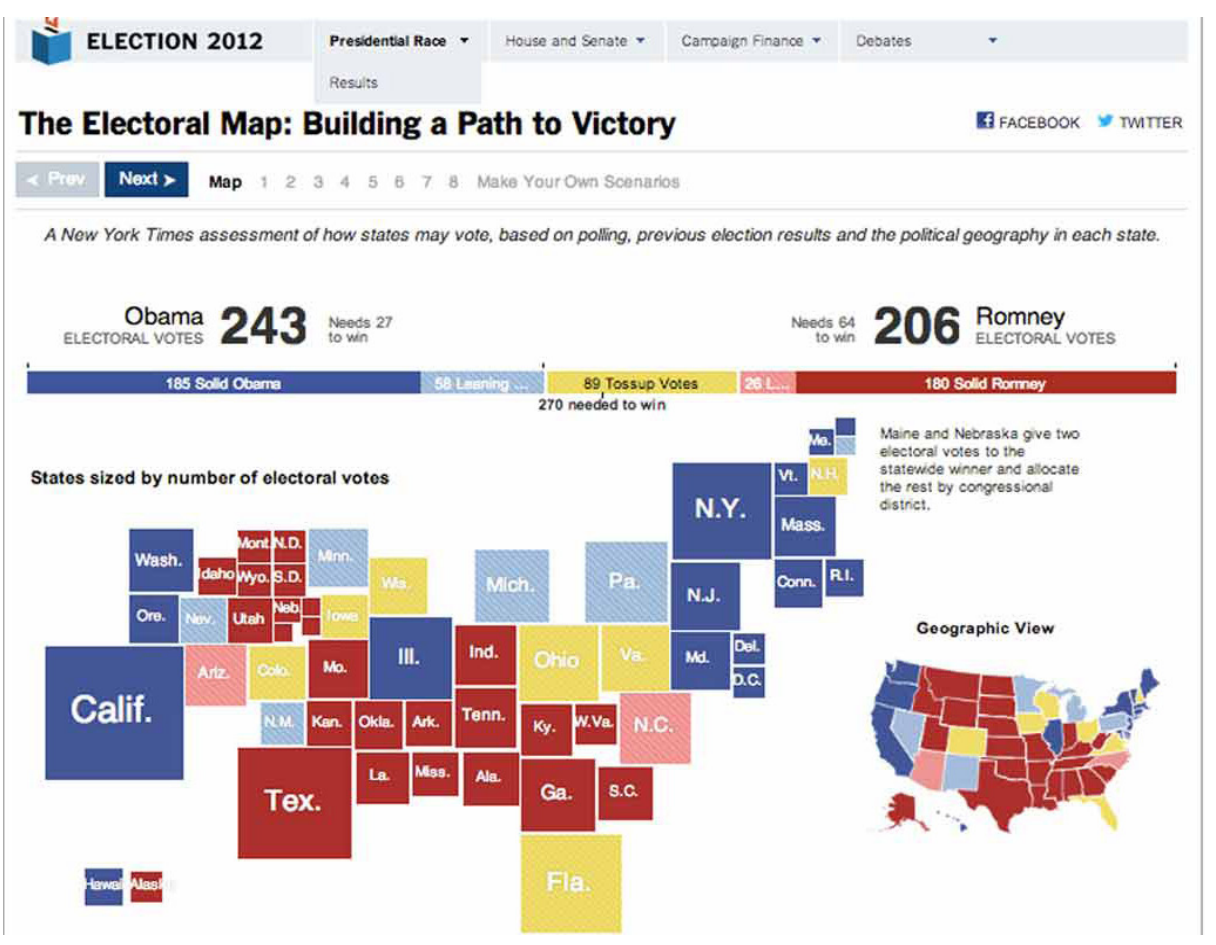

Nas telas seguintes do infográfico, nota-se uma modificação na organização visual da informação e observa-se uma estrutura de slideshow interativo (Segel \& Heer, 2010) que é uma sequência interligada de slides que representam diferentes unidades significativas conectadas. Há um total de oito slides que podem ser acessados linearmente por meio de botões de avançar e retroceder ou por meio dos botões numéricos (de 1 a 8). Em cada um dos slides é apresentado um cenário eleitoral, isto é, uma previsão de caminhos prováveis ou até mesmo inesperados para as Eleições com base em análises feitas pelos jornalistas. No slide número dois (Figura 4), por exemplo, narra-se uma situação hipotética de vitória de Obama em cima de Romney por 359 a 179 votos, caso o primeiro candidato seja vencedor nos mesmos estados que lhe garantiram a presidência nas Eleições presidenciais anteriores. 
Figura 4 Lógica das mediações em The Electoral Map. (Fonte: The New York Times, 2012).

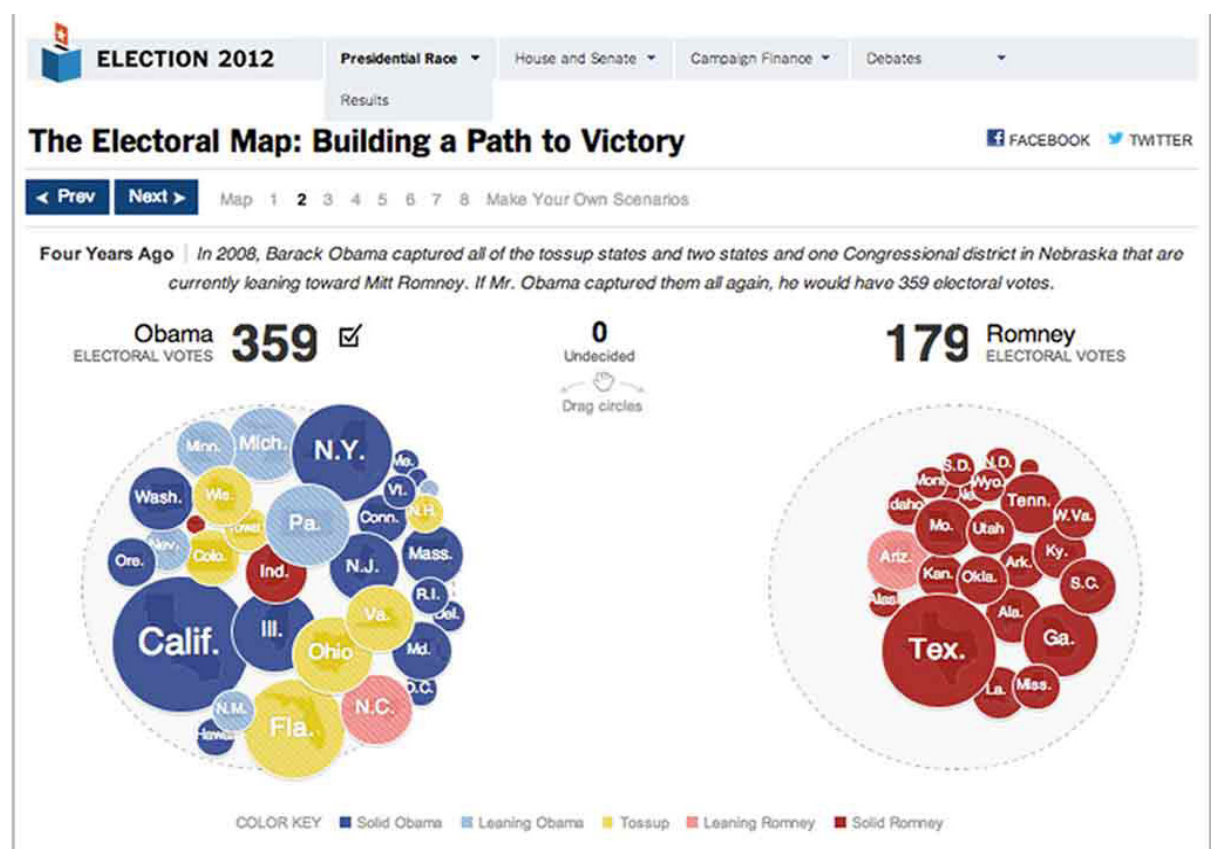

Tanto na tela inicial do infográfico (Map), como nas telas seguintes que compõem o slideshow, a lógica comunicacional enfatizada é a das mediações. Embora existam alguns recursos interativos nessas telas como roll over, que permite aos usuários acessarem unidades informativas secundárias ao passar o cursor do mouse sobre áreas ativas, o que sobressai são os elementos da narrativa e do discurso jornalístico que direcionam o percurso de compreensão daqueles que consumem a informação.

Ao passar para a última tela denominada Make your own scenarios observa-se, finalmente, uma mudança de lógica comunicacional: o infográfico supera a abordagem marcada pela mediação imposta pelos seus produtores (jornalistas e designers) para alcançar aportes mais abertos, construtivos e negociados da informação. Nesta tela, o usuário é convidado a participar do processo comunicacional e partilhar suas opiniões sobre os resultados eleitorais.

O próprio título da tela - Monte seu próprio cenário - já é indicativo de que se trata de uma lógica comunicacional de SenseMaking: o consumidor-usuário pode se empoderar para construir uma realidade que não lhe é mais totalmente entregue em canais unidirecionais, mas sim construída conjuntamente, mediante os esforços coletivos das partes interagentes. Em um primeiro momento de interação nesta tela, o consumidor-usuário manipula e distribui, para os candidatos presidenciais, os círculos coloridos que correspondem, cada um, aos estados norte-americanos e suas respectivas representatividades. Essa customização dos elementos gráficos na tela gera novas configurações visuais que representam, semanticamente, hipotéticos encaminhamentos eleitorais. A Figura 5 ilustra duas possíveis configurações visuais do infográfico que 
correspondem a cenários políticos opostos: no frame à esquerda, a distribuição dos círculos - sobretudo os em amarelo, que indicam estados indecisos em pesquisas - decide o resultado das eleições a favor do candidato democrata Obama em um placar de 332 votos contra 206; já no frame à direita, uma improvável, mas possível mudança no cenário político desloca o estado da Califórnia, tendencialmente democrata e com sólida força eleitoral, para o partido republicano. Junta-se a esse cenário uma possível vitória de Romney em estados indecisos, como Flórida e Ohio, e a vitória geral é do partido republicano, em um placar de 308 votos contra 230.

Figura 5 Lógica do Sense-Making em The Electoral Map. Fonte: The New York Times, 2012.
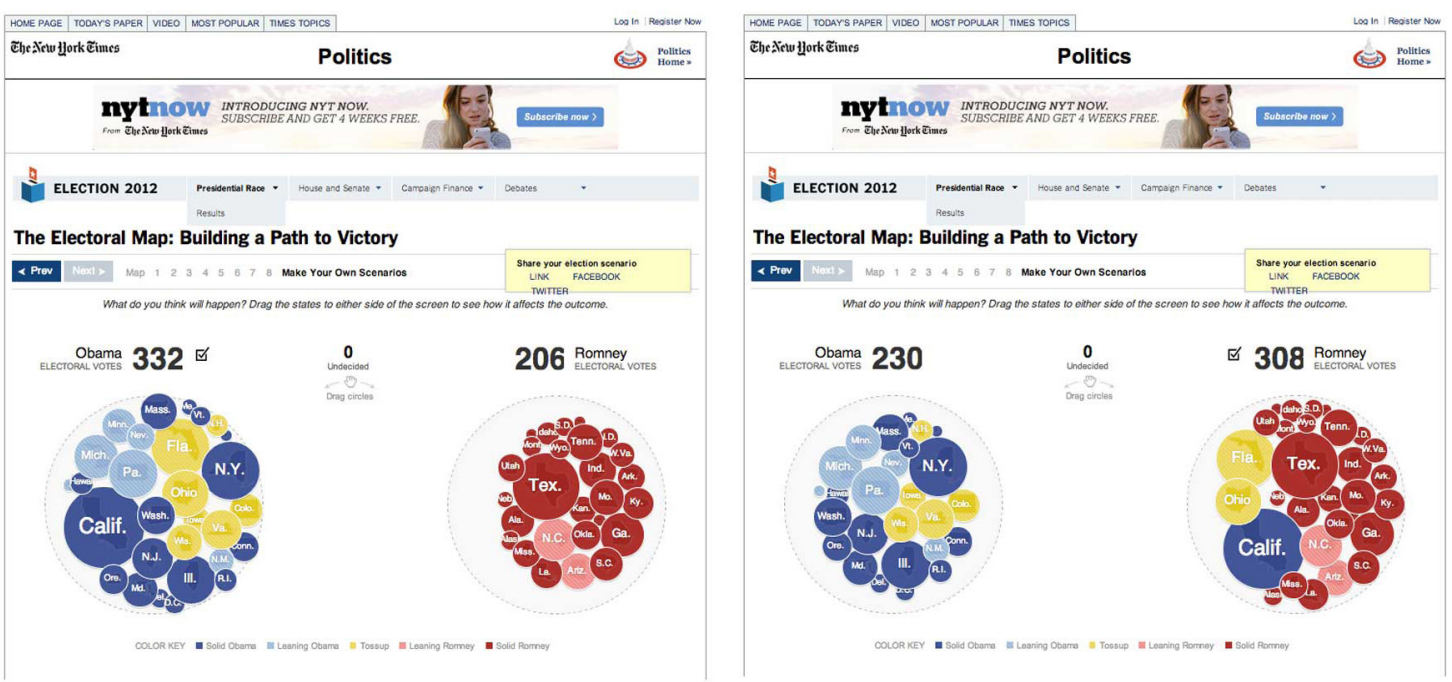

Ao final da distribuição dos círculos, e suas respectivas preferências partidárias, consumidores-usuários visualizam possíveis resultados eleitorais que eles próprios projetaram, amparados, ou não, em informações previamente transmitidas pelos produtores da informação. Os consumidores-usuários podem, finalmente, compartilhar suas previsões ou desejos eleitorais nas redes sociais (Twitter ou Facebook) (Figura 6).

8 Disponível em: <https://twitter.com/ juliagiannella>. Acesso em mar. 2015.
Figura 6 Compartilhamento e ressignificação da informação. Fonte: Twitter, $2015^{8}$.

Júlia Giannella @juliagiannella · $3 \mathrm{~m}$

In my scenario for the 2012 election, Obama wins, with 332 electoral votes. What's yours? elections.nytimes.com/2012/ratings/e... via @nytimes 


\section{Considerações finais}

Como se buscou evidenciar, há, no atual cenário de excesso de dados, a demanda para os produtores da informação (designers e comunicadores em geral) atuarem como mediadores do processo comunicativo, reduzindo a complexidade informativa gerada pelo fluxo e cruzamento de dados, ao retratar a realidade sobre um ponto de vista. Paralelamente, observa-se a emergência de práticas de comunicação alternativas, multilineares e descentralizadas, permitidas pelo modelo circulatório que a web constitui e pelos recursos interativos do ambiente digital, que possibilitam aos consumidores construir ressignificações e outros usos sociais sobre a informação que consome. Pode-se, portanto, problematizar os produtos do Design da Informação em torno de duas lógicas comunicacionais que atuam sobre eles: 1) a narrativa mediada pelos produtores, que constrói uma hierarquização dos enunciados com objetivo de facilitar e direcionar a compreensão de informações e 2) o Sense-Making que engaja o consumidor no processo de significação da mensagem e na construção/destruição de lacunas em seu conhecimento.

A polarização, não excludente, entre duas lógicas comunicacionais - das mediações e do Sense-Making - desdobra-se no conflito entre procedimentos de controle versus ações de abertura estabelecidos pelas mídias e seus produtos midiáticos e possibilitados pelos avanços tecnológicos de uma cultura cada vez mais interativa e colaborativa.

\section{Referências}

BERTIN, J. La Graphique. Communications. Paris, n. 15, p.169-185, 1970. BONSIEPE, G. Design as a tool for cognitive metabolism: from knowledge production to knowledge participation. International Symposium on the Dimensions of Industrial Design Research, Milano, Politecnico di Milano, 2000.

BRAGA, J. L. Interação como contexto da Comunicação. MATRIZES, São Paulo, ano 6, n. 1, : 21-41, 2012.

COSTA, J. La Esquemática. Barcelona: Paidós, 1998.

DERVIN, B. Chaos, order, and sense-making: a proposed theory for information design. In: JACOBSON, R. (Org.). Information Design. Cambridge: MIT Press, 2000, p. 35-57.

FAUSTO NETO, A. As bordas da circulação. Alceu, Rio de Janeiro, v. 10, n. 20, p. $55-69,2010$.

FRASCARA, J. ¿Qué es el diseño de información? 1a ed. Buenos Aires: Infinito, 2011.

GIANNELLA, J. R. 2014. Dispositivo infovis: interfaces entre visualização da informação, infografia e interatividade em sítios jornalísticos.189 f. Dissertação (Mestrado) - Escola de Comunicações e Artes - Universidade de São Paulo, 2014. 
HORN, R. Information Design: emergence of a new profession. In: JACOBSON, R. (Org.). Information Design. Cambridge: MIT Press, 2000. p. 15-33.

MARTÍN-BARBERO, J. De los medios a las mediaciones. Barcelona: Gustavo Gili, 1987.

MEGGS, P. B.; PURVIS, A. W. História do Design Gráfico. São Paulo: Cosac Naify, 2009.

PASQUALL, A. Um breve glossário descritivo sobre comunicação e informação. In: MARQUES DE MELO, J.; SATHLER,L. Direitos à Comunicação na Sociedade da Informação. São Bernardo do Campo: Unesp, 2005.

SEGEL, E.; HEER, J. Narrative Visualization: telling stories with data. IEEE Transactions on Visualization and Computer Graphics, v. 16, p. 1139$1148,2010$.

SHEDROFF, N. Information interaction design: a unified field theory of design. In: JACOBSON, Robert (Org.). Information Design. London: MIT Press, 2000, p. 267-292.

WURMAN, R. S. Ansiedade de informação. Como transformar informação em compreensão. São Paulo: Cultura Editores Associados, 1991.

\section{Sobre as autoras}

\section{Júlia Rabetti Giannella}

Doutoranda em Design pela ESDI, Escola Superior de Desenho Industrial da Universidade do Estado do Rio de Janeiro. Mestre em Ciências da Comunicação pela Universidade de São Paulo. Possui interesse investigativo em Design da Informação, Design de Interface, Visualização de dados e Cartografia digital.

<juliagiannella@gmail.com>

\section{Sandra Souza}

Livre-docente na Escola de Comunicações e Artes da Universidade de São Paulo, atua nas áreas de Propaganda e Publicidade, Comunicação Visual e Marketing, em graduação e pós-graduação, e lidera o GEIC, Grupo de Estudos da Imagem em Comunicação.

<smrdsouz@usp.br>

Artigo recebido em 20 mar. 2015, aprovado em 07 jul. 2015. 